\title{
Aberrations in Placental Cytokine mRNA Related to Intrauterine Growth Retardation
}

\author{
MIRJANA HAHN-ZORIC, HENRIK HAGBERG, INGEMAR KJELLMER, JOY ELLIS, \\ MARGARETA WENNERGREN, AND LARS Å. HANSON \\ Department of Clinical Immunology, Göteborg University, S-413 46 Göteborg [M.H.-Z., L.A.H.], \\ Department of Obstetrics and Gynecology [H.H., J.E., M.W.], and Department of Pediatrics [I.K.], \\ Göteborg University, S-416 85 Göteborg, Sweden
}

\begin{tabular}{|c|c|}
\hline \multicolumn{2}{|c|}{ ABSTRACT } \\
\hline $\begin{array}{l}\text { During normal pregnancy, a predominance of Th } 2 \text { type cy- } \\
\text { tokines prevails and is considered to protect the fetus. Animal } \\
\text { experiments suggest that an increase of Th } 1 \text { type cytokines may } \\
\text { instead have deleterious effects. We have studied with the reverse } \\
\text { transcription PCR technique mRNA for IL- } 1 \alpha \text {, IL- } 1 \beta \text {, IL- } 6 \text {, IL- } 8 \text {, } \\
\text { IL-10, transforming growth factor- } \beta \text {, tumor necrosis factor- } \alpha \text {, } \\
\text { and interferon- } \gamma \text { in placentas from full-term appropriately grown } \\
\text { newborns, newborns with intrauterine growth retardation (IUGR) } \\
\text { and newborns who were only small for gestational age. The } \\
\text { mRNA for IL-10 was significantly reduced in the IUGR placen- } \\
\text { tas }(p<0.05 \text { ), whereas the mRNA for IL- } 8 \text { was significantly } \\
\text { higher ( } p<0.05 \text { ) for the IUGR cases compared with the } \\
\text { full-term neonates. It might be that reduced IL-10 in the placenta } \\
\text { is involved in the pathogenesis of IUGR. (Pediatr Res 51: } \\
\mathbf{2 0 1 - 2 0 6 , ~ 2 0 0 2 )}\end{array}$ & $\begin{array}{l}\text { Abbreviations } \\
\text { AGA, appropriate for gestational age } \\
\text { DEPC, diethyl pyrocarbonate } \\
\text { dNTP, deoxynucleotide triphosphate } \\
\text { EtBr, ethidium bromide } \\
\text { IFN, interferon } \\
\text { IUGR, intrauterine growth retardation } \\
\text { KO, knock-out } \\
\text { pd(N), random hexamer primer } \\
\text { PE, preeclampsia } \\
\text { RT-PCR, reverse transcription PCR } \\
\text { SGA, small for gestational age } \\
\text { TBE, tris-borate-EDTA } \\
\text { TGF, transforming growth factor } \\
\text { Th1, T helper type 1 } \\
\text { Th2, T helper type } 2 \\
\text { TNF, tumor necrosis factor }\end{array}$ \\
\hline
\end{tabular}

Lately it has been realized that cytokines provide important signals during pregnancy for the implantation of the egg, trophoblast growth, hormone production, and, finally, for the induction of delivery via prostaglandins $(1,2)$. A predominance of Th2-derived cytokines (i.e. IL-4, IL-10, and TGF- $\beta$ ) appears to characterize the normal pregnancy, whereas indications of a shift of balance in favor of Th1-derived cytokines (i.e. IL-2, IFN- $\gamma$, and TNF- $\alpha$ ) has been reported in a few pathologic pregnancies $(2,3)$. Increased placental exposure to IFN- $\gamma$ and TNF- $\alpha$ from trophoblast-activated lymphocyte supernatants from women with unexplained recurrent abortions may impair fetal development in mice, either as IUGR or resorption of the fetus (4). In experimental animals, it was

Received May 31, 2000; accepted July 3, 2001.

Correspondence: Mirjana Hahn-Zoric, Department of Clinical Immunology, University of Göteborg, Guldhedsgatan 10, S-413 46 Göteborg, Sweden; e-mail: mirjana.hahn-zoric@immuno.gu.se

This study was supported by grants from the Swedish Agency for Research Cooperation with Developing Countries (SAREC) and Swedish Medical Research Council (No 215). noted that TNF- $\alpha$, IFN- $\gamma$, and IL- 2 can increase fetal resorption, whereas IL-3 and granulocyte-macrophage colony stimulating factor injected in abortion-prone mice seemed to have a trophic effect on the placenta, thus increasing fetal and placental weight (5). The same mouse strain prone to habitual abortion turned out to be deficient in local IL-10 production and the abortions were prevented by IL-10 (6). In IL-10deficient mice, generated by gene targeting, most animals are growth retarded and suffer from chronic enterocolitis (7), but there seems to be no reports concerning intrauterine growth in IL-10 KO animals. The IL-10 KO litters appear normal in number and the offspring are normal in size. It seems that the growth retardation occurs in conjunction with developing inflammation in the gut (D. Rennick, personal communication). On the other hand, it was shown that neutralization of IL-10 by administration of anti-IL-10 MAb to pregnant mice did not affect duration of gestation or the fetal outcome. However, neonates exposed to anti-IL-10 MAb in utero showed transient 
growth deficiency (8). Available information from humans is mainly derived from studies on cytokine levels in blood.

In the present study, we have analyzed mRNA for Th1 and Th2 cytokines in placentas comparing AGA, SGA, and IUGR neonates to test the hypothesis that IUGR in humans may be connected to a predominance of cytokines from the Th1 group.

\section{METHODS}

Collection and handling of placentas. Placentas were obtained from 34 normal term deliveries resulting in AGA babies, 20 IUGR deliveries (11 without and 9 with PE), and 7 SGA deliveries ( 4 without and 3 with PE). All IUGR babies but one were delivered by cesarean section, and 4 out of 7 SGA babies were delivered vaginally. In the control group, there were 23 vaginal deliveries, 9 cesarean sections, and for 2 the mode of delivery was not clearly specified. There were no signs of infection or inflammation, either in any of the study groups or in the controls. Gestational ages of the study groups varied between 26 and $41 \mathrm{wk}$, whereas the control group consisted of term babies only. No neonates with malformations or any other reason for low birth weight than PE were included.

SGA and IUGR infants weighed at least $22 \%$ less than normal at their respective gestational ages. Most SGA and IUGR infants were diagnosed during pregnancy after repeated ultrasound examinations. IUGR was defined as lack of increase in estimated fetal weight $(\leq 11 \%$ compared with standard curves, examination interval $\geq 12 \mathrm{~d}$ ) and/or pathologic Doppler velocimetry in the umbilical artery. Small fetuses with normal increase of estimated weight compared with standard curves and normal Doppler velocimetry in the umbilical artery were classified as SGA $(9,10)$.

PE was defined as arterial blood pressure exceeding 140/90 in the presence of significant albuminuria $(>0.3 \mathrm{~g} / 24 \mathrm{~h})$, with onset after 20 full weeks of pregnancy.

After delivery, the placenta was placed on ice and the time until the samples were frozen was a maximum of $15 \mathrm{~min}$. Between 50 and $100 \mathrm{mg}$ of tissue were dissected from trophoblast or "fetal placenta" and decidua or "maternal placenta," avoiding connective tissue and blood vessels. The tissue was rinsed in a physiologic salt solution and frozen at $-70^{\circ} \mathrm{C}$. Samples were then transferred to liquid nitrogen, where they were stored until tested.

The RNA was isolated and analyzed with RT-PCR technique for the relative quantification of gene expression of IL-1 $\alpha$, IL- $1 \beta$, IL-6, IL-8, IL-10, TGF- $\beta 1$, TNF- $\alpha$, and IFN- $\gamma$, using for comparison a simultaneously amplified sequence of the housekeeping gene glyceraldehyde 3-phosphate dehydrogenase (G3PDH).

We analyzed separately the samples from the trophoblast and from the decidua from the placentas in each group. We did not isolate certain cell populations, but used the whole tissue samples either from trophoblast or decidua for the isolation of total RNA.

$\boldsymbol{R N A}$ preparation. Total RNA enriched for mRNA was isolated from the tissue by a single-step method with a readyto-use reagent (RNA STAT-60, Tel Test B, Friendswood TX, U.S.A.), which includes phenol and guanidinium thiocyanate in a monophase solution. Isolation by this method according to the manufacturer includes the following steps: homogenization of the tissue, RNA extraction with chloroform, RNA precipitation with isopropanol, and RNA wash with ethanol. Then the isolate was treated with RQ1 RNase-free DNase (Promega, Madison, WI, U.S.A.) to remove possible remnants of genomic DNA from the sample and another extraction of RNA was carried out.

The yield and purity of isolated RNA was determined from spectrophotometric measurements of absorbances at 260 and 280, as well as 230 and $270 \mathrm{~nm}$ wavelengths. RNA was checked for quality on a 3\% agarose gel with EtBr (Sigma Chemical, St. Louis, MO, U.S.A.) and in the presence of a RNA standard (Human HeLa Cell Total RNA, CLONTECH, Palo Alto, CA, U.S.A.). If the isolated RNA was found to have distinct $28 \mathrm{~S}$ and $18 \mathrm{~S}$ ribosomal bands, it was considered intact and of good quality.

Reverse transcription. For cDNA synthesis, $2 \mu \mathrm{g}$ of RNA and $\operatorname{pd}(\mathrm{N})_{6}$ (Pharmacia-Upjohn, Uppsala, Sweden) were used. A mixture of dNTPs (Pharmacia-Upjohn), RNase inhibitor from placenta (Promega), Superscript (reverse transcriptase, Invitrogen, Carlsbad, CA, U.S.A.), first strand buffer (Invitrogen), and DEPC-treated water $\left(\right.$ DEPC- $\left.\mathrm{H}_{2} \mathrm{O}\right)$ (Sigma Chemical) were added to a total volume of $30 \mu \mathrm{L}$.

$\boldsymbol{P C R}$. For each cytokine, commercially available specific primers and positive controls (CLONTECH) were used. The primer sequences are listed below:

IL-1 $\alpha$

Upstream 5' CAAGGAGAGCATGGTGGTAGTAGCAACCAACG 3'

Downstream 5' TAGTGCCGTGAGTTTCCCAGAAGAAGAGGAGG 3'

IL- $1 \beta$

Upstream 5' ATG GCA GAA GTA CCT AAG CTC GC 3' Downstream 5' A CAC AAA TTG CAT GGT GAA GTC AGT T 3'

IL-6

Upstream 5' ATG AAC TCC TTC TCC ACA AGC GC 3' Downstream 5' G AAG AGC CCT CAG GCT GGA CTG 3' IL-8

Upstream 5' ATG ACT TCC AAG CTG GCC GTG GCT 3' Downstream 5' T CTC AGC CCT CTT CAA AAA CTT CTC 3'

IL-10

Upstream 5' AAGCTGAGAACCAAGACCCAGACATCAAGGCG 3'

Downstream 5' AGCTATCCCAGAGCCCCAGATCCGATTTTGG 3'

TGF- $\beta 1$

Upstream 5' GCC CTG GAC ACC AAC TAT TGC T 3' Downstream 5' AG GCT CCA AAT GTA GGG GCA GG 3' TNF- $\alpha$

Upstream 5' GAG TGA CAA GCC TGT AGC CCA TGT TGT AGC A 3'

Downstream 5' GCA ATG ATC CCA AAG TAG ACC TGC CCA GAC T 3'

IFN- $\gamma$ 
Upstream 5' GCATCGTTTTGGGTTCTCTTGGCTGTTACTGC $3^{\prime}$

Downstream 5' CTCCTTTTTCGCTTCCCTGTTTTAGCTGCTGG 3'

PCR amplification of $2 \mu \mathrm{L}$ cDNA was performed in the presence of AmplyTaq Gold DNA Polymerase, PCR buffer, $2.0 \mathrm{mM} \mathrm{MgCl} 2$ (all from PerkinElmer Cetus, Norwalk CT, U.S.A.), dNTP mix (Pharmacia), and sterile water in a total volume of $50 \mu \mathrm{L}$. The PCR was performed in a PerkinElmer Cetus GeneAmp PCR System 9600. The first step was incubation at $95^{\circ} \mathrm{C}$ for $12 \mathrm{~min}$, then 35 cycles of denaturation at $94^{\circ} \mathrm{C}$ for $45 \mathrm{~s}$, annealing at $65^{\circ} \mathrm{C}$ for $45 \mathrm{~s}$, and extension at $72^{\circ} \mathrm{C}$ for $2 \mathrm{~min}$, followed by final extension for $7 \mathrm{~min}$ at $72^{\circ} \mathrm{C}$.

Negative controls consisted of samples in which the reverse transcriptase was omitted to detect possible contamination by genomic DNA and controls in which cDNA was replaced by sterile $\mathrm{dH}_{2} \mathrm{O}$.

Gel electrophoresis of the PCR products. The PCR products were stored at $4^{\circ} \mathrm{C}$ until tested by submarine electrophoretic separation in TBE buffer. Ten microliters of sample were mixed with $5 \mu \mathrm{L}$ of gel loading solution (Sigma Chemical) on a 3\% agarose gel (SeaKem and NuSieve, FMC Bioproducts, Rockland, ME, U.S.A.) containing EtBr (Sigma Chemical) and in the presence of the molecular size marker $\Phi$ X174/HaeIIIdigested DNA (Invitrogen). The gels were photographed in the dark by Polaroid MP 4+ Instant Camera System (Sigma Chemical) under illumination of UV light.

Analysis of the detected signals. Gel images were scanned (StudioScan II/si, Agfa) and densitometric analysis, i.e. quantification of bands in terms of position, height and area in two dimensions, referred to as "volume" analysis, was performed with IPLab Gel software for Macintosh (BioSystematica, Plymouth, U.K.). The results were expressed as a ratio calculated from the "volume" of the amplified cytokine gene product divided by the "volume" of the amplified housekeeping gene product in the same sample.

Statistical analyses. Data were analyzed by nonparametric Mann-Whitney $U$ test and Dunn's test for nonparametric multiple comparisons for unequal sample sizes. Spearman's rank correlation was used for the association analyses. Medians were used for all analyses.

Ethics. This study was conducted with informed consent of the patients and approved by the ethics committee.

\section{RESULTS}

We found a significant reduction of IL-10 mRNA expression in the decidua of the IUGR placentas compared with the control material ( $p<0.05$, Fig. 1). In parallel, the IL-8 mRNA expression was significantly higher in the decidua of the IUGR placentas $(p<0.05)$ compared with the control group (Fig. 2).

The ratio between the IL- 8 and IL-10 mRNA expression was significantly higher both in the decidua and the trophoblast of the IUGR compared with the control placentas $(p<0.01$ and $<0.05$, respectively) (Table 1 ). There was a negative correlation between the expression of mRNA levels for IL-8 and IL-10 in the decidua of the IUGR placentas, although it was not statistically significant. Thus, this showed a trend that the
IL-10 mRNA gene expression in placenta

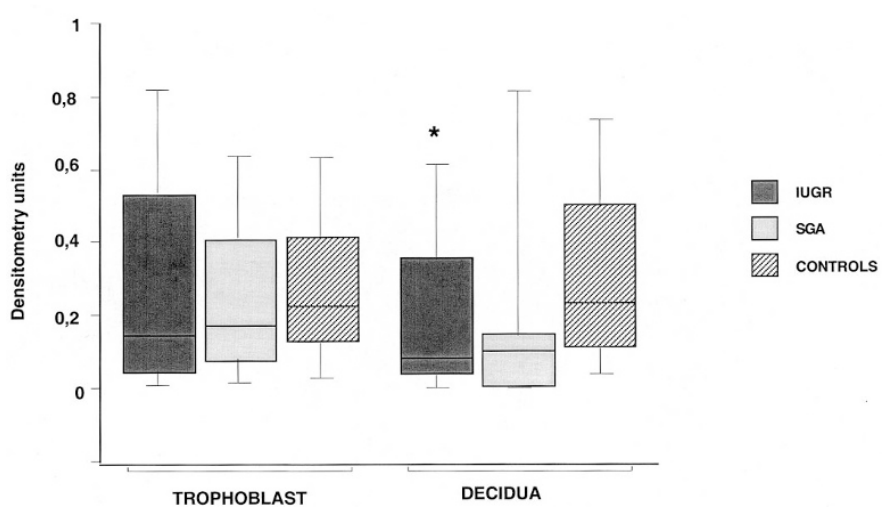

Figure 1. IL-10 mRNA expression in trophoblast and decidua samples from normal and pathologic placentas. The IL-10 mRNA levels in decidua of the IUGR group were significantly lower compared with the controls $\left({ }^{*} p<0.05\right)$. The IL-10 mRNA expression in the SGA placentas was not significantly lower compared with either controls or the IUGR group. Medians and 25-75\% confidence intervals are indicated.

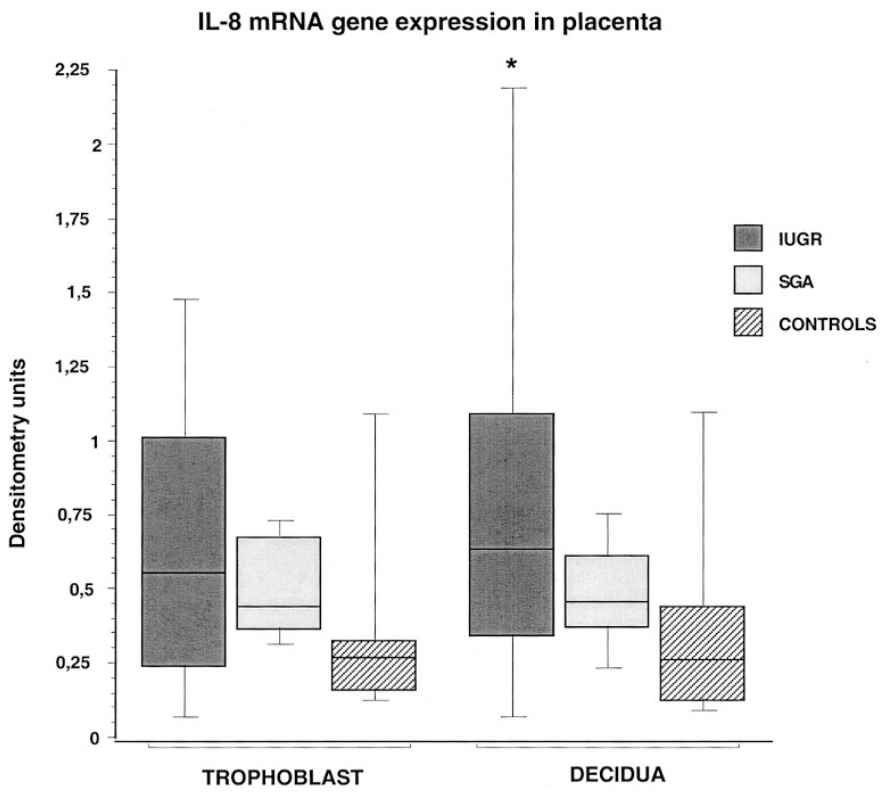

Figure 2. IL-8 mRNA expression in trophoblast and decidua samples from normal and pathologic placentas. In the decidua of the IUGR group, the IL-8 mRNA levels were significantly higher compared with the controls $\left({ }^{*} p<\right.$ 0.05). There was no significant difference in IL-8 mRNA levels between the SGA and either controls or IUGR groups. Medians and 25-75\% confidence intervals are indicated.

individuals with lower IL-10 had higher IL-8 mRNA levels in the decidua and vice versa.

We divided the IUGR group into the two subgroups, individuals with PE during pregnancy and those without PE. Individuals from the IUGR group with PE had significantly lower IL-10 mRNA levels in the decidua $(p=0.05)$, and significantly higher IL-6 mRNA levels in the trophoblast compared with the controls $(p<0.05$; Fig. 3 and Table 1).

Individuals with IUGR but no PE during pregnancy had significantly higher IL-8 mRNA levels in the decidua ( $p<$ 0.01; Table 1). The ratios of the mRNA levels for the pro-/ 


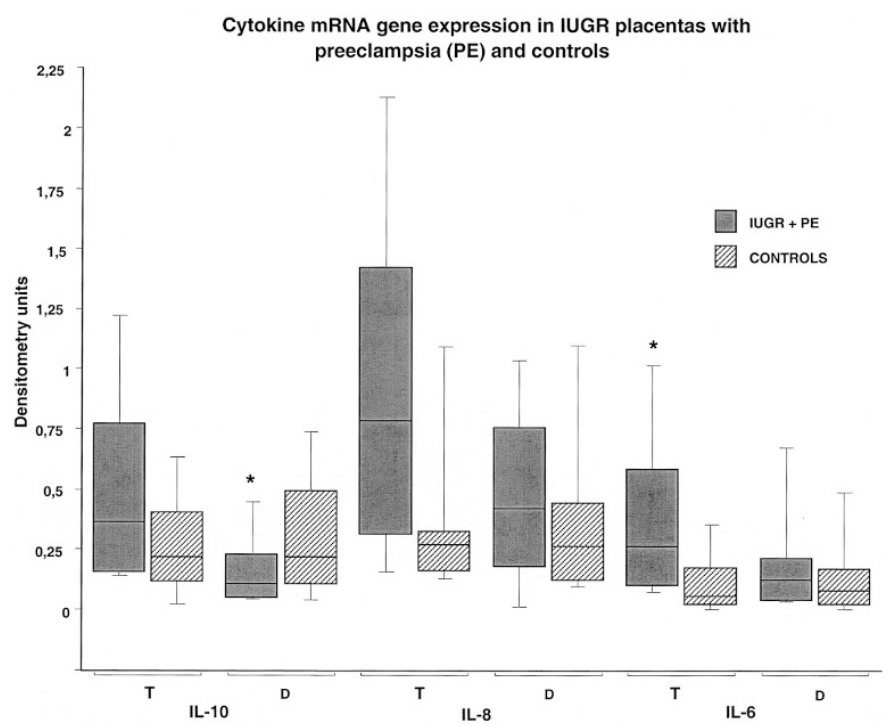

Figure 3. Cytokine gene expression in IUGR placentas from PE cases and control placentas. The mRNA for IL-10 was significantly lower in the decidua of the IUGR group with PE compared with the controls $(* p<0.05)$. The mRNA for IL-6 was significantly higher in the trophoblasts of the IUGR placentas with PE compared with the controls $\left({ }^{*} p<0.05\right)$. $D$, decidua, $T$, trophoblast. Medians and $25-75 \%$ confidence intervals are indicated.

anti-inflammatory cytokines were significantly higher in the decidua of these individuals compared with the controls $(p<$ 0.05; Table 1).

When the IUGR group with PE was compared with the IUGR group without PE during pregnancy, the IL-6 mRNA levels were significantly higher in the trophoblast of the group with PE than in the group without PE $(p<0.02)$. The mRNA levels of the two anti-inflammatory cytokines (IL-10 and TGF- $\beta$ ) were also higher in the trophoblast of the IUGR individuals with PE compared with those without PE $(p<$ 0.01 ). In contrast, the mRNA levels of the proinflammatory cytokines (IL- $1 \alpha$, IL- $1 \beta$, IL- 8 , IFN- $\gamma$, and TNF- $\alpha$ ) in the decidua were significantly lower in the group with IUGR and PE compared with the group without PE $(p<0.03)$. Likewise, the ratios between the mRNA levels of the pro-/antiinflammatory cytokines were significantly lower in the decidua from the group with PE $(p<0.02$; Table 1).

Although there was a lower IL-10 mRNA expression and a higher IL-8 mRNA expression both in the decidua and the trophoblast of the SGA placentas, they were too few in number (seven samples only) and the variations between individuals were too large to reach any significant differences. Therefore we analyzed the placentas from the two groups of small neonates (comprised of the IUGR and SGA neonates) together in comparison to the placentas of normal size newborns (Table $1)$. The IL-10 mRNA levels in the decidua were significantly lower $(p<0.05)$ and the IL-8 mRNA levels were significantly higher both in the trophoblast and the decidua compared with the controls ( $p<0.05$ and $p<0.01$, respectively). The ratios of the IL-8/IL-10 mRNA levels in the trophoblast and the decidua samples from the placentas of the small children were significantly higher compared with the controls $(p<0.01)$. There was a negative correlation between IL-10 and IL-8
mRNA expression in the decidua of these children, although not statistically significant.

The placentas of the small newborns (IUGR and SGA) whose mothers had PE had significantly higher levels of IL-6 mRNA in the trophoblast $(p<0.05)$, as did the placentas of the mothers from the group with PE and IUGR alone (Table 1). The IL-8 mRNA levels were also higher in the trophoblast samples of this group compared with the controls $(p<0.01$; Table 1).

Expression of mRNA for IL- $1 \alpha$, IL- $1 \beta$, and IFN- $\gamma$ was rather low in all the placentas, whereas the expression of TGF- $\beta$ was extremely high in comparison with the expression of other cytokines, although the levels did not differ significantly between the groups.

\section{DISCUSSION}

This study supports the concept that there may be a decrease of IL-10 mRNA in the placenta of IUGR neonates. Previous reports have suggested that the protein levels may also be decreased. Thus, a decreased production of IL-10 from peripheral blood monocytes was found in a few pregnancies with growth-retarded fetuses of not clearly defined nature (3). In animal studies, a strain of abortion-prone mice was found deficient in placental production of IL-10 (6). Furthermore, in normal murine pregnancies, administration of anti-IL-10 MAb was associated with transient neonatal growth retardation, although it did not alter the duration of gestation or the fetal outcome (8).

A low IL-10 level in the placenta might result in an increase in Th1 cells with an elevated production of the cytokines IFN- $\gamma$, TNF- $\alpha$, and IL-2. This may have damaging effects on the fetus causing either impaired growth, or abortion, or resorption of the fetus (2). On the other hand, the cytokines of the colony stimulating factor family may reduce the damage and even increase fetal and placental weight (5), possibly by effects on the placenta similar to those of IL-10.

In IL-10 gene $\mathrm{KO}$ mice, exaggerated inflammation occurs (11). Immunoreactive cells (activated macrophages, Th1 cells, and natural killer cells) from peripheral tissues of these animals when stimulated in culture produce 3 to 20 -fold more IL-6, TNF- $\alpha$, and IFN- $\gamma$ than the cells from control mice. This suggests that the deficiency of IL-10 also in the placenta might result in elevated levels of, e.g. IFN- $\gamma$ and TNF- $\alpha$, increasing the risk of fetal damage. Such an imbalance between Th1 and Th2 cytokines in the placenta may also be harmful in human pregnancies. Indeed, in a recent study of women with unexplained recurrent spontaneous abortion, significantly lower levels of the Th2 cytokines IL-10 and IL- 6 and significantly higher levels of the Th1 cytokine IFN- $\gamma$ were detected compared with normal pregnancy (12). Moreover, another study showed a difference in cytokine production by stimulated peripheral blood mononuclear cells between mothers with normal and abnormal pregnancies (3). A significantly increased production of IL-2 and IFN- $\gamma$ and a decrease of IL-10 were seen in pathologic pregnancies with abortions, or SGA babies, compared with normal pregnancies. 


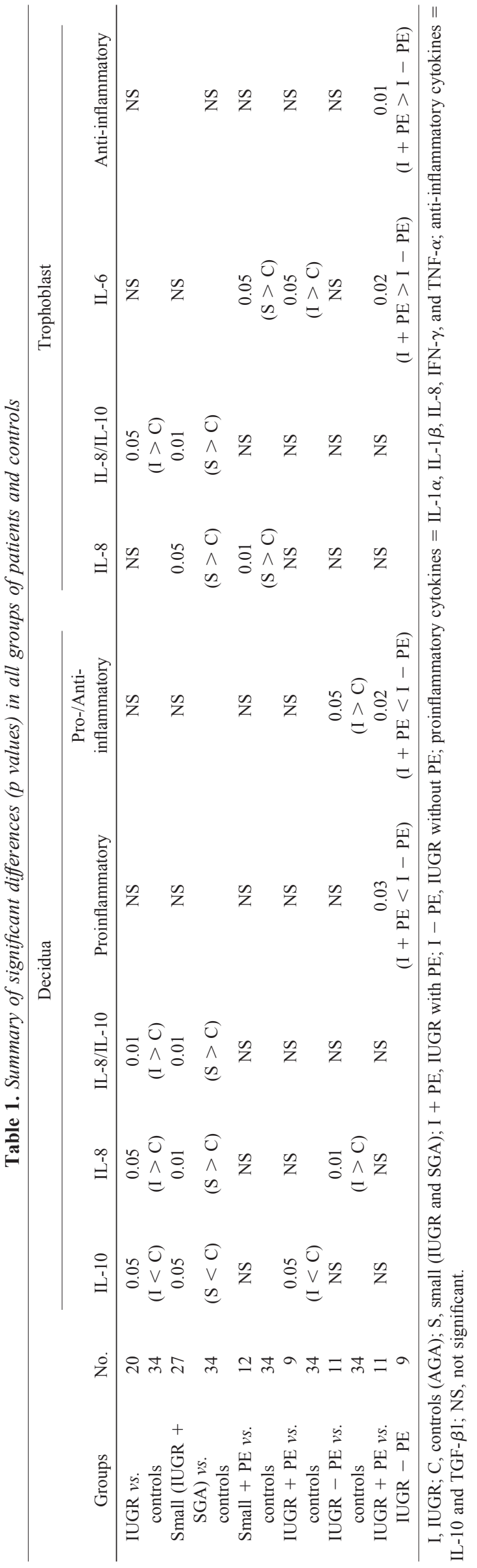

Is the low expression of IL-10 in placentas from IUGR pregnancies a primary change or secondary to an increase of pro-inflammatory cytokines from the Th1 cells caused by hypoxia? TNF- $\alpha$ and IL-1 are markedly stimulated by hypoxia in villous explants of the human placenta (13). But in our study, no changes consistent with such results were found. Therefore, the reduced IL-10 expression may be a primary event.

If a deficiency in placental IL-10 really is related to the pathogenesis of IUGR in humans, one might consider using IL-10 therapeutically. Actually, IL-10 can be given to humans without significant untoward effects, and it may reduce IFN- $\gamma$ and TNF- $\alpha$ levels $(14,15)$. Furthermore, it has been noted in an animal model that IL-10 biosynthesis may be increased with large doses of methylprednisolone (16).

We may speculate that the significant increase in the ratios of mRNA levels of the pro-inflammatory cytokines to the anti-inflammatory cytokines, which we see in the decidua of the IUGR group compared with the controls, might be caused by the low levels of IL-10 that may not be sufficient to dampen the inflammatogenic effects.

It has been suggested that normal pregnancy itself stimulates an inflammatory response and that PE is what happens when, toward the end of pregnancy, this inflammatory response becomes exaggerated (17). Furthermore, a decrease in IL-10 and an increase in TNF- $\alpha$ both in serum and in trophoblast were reported in PE compared with normal pregnancy (18). This phenomenon may be associated with increased maternal antifetal immunity and thus inadequate placental development in PE. The deficiency of placental IL-10 in PE is in good agreement with our findings.

We also observed higher mRNA levels of IL- 6 only in the trophoblast of individuals with PE during pregnancy. This corroborates the report that significantly elevated levels of IL-6 and IL-8 were found in mid-trimester amniotic fluid of the future preeclamptic group compared with the normal pregnancies (19).

The higher production of placental mRNA for IL-8 in the IUGR cases may be a result of the cytokine imbalance. IL- 8 is produced in increased amounts at delivery, presumably both to protect the damaged intrauterine surfaces after delivery via its strong chemotactic effect on neutrophils and to repair via its angiogenic effect $(20,21)$. IL-8 also potentiates production of neutrophil-derived collagenase required in helping ripening and opening of the cervix at delivery (22-24).

Further studies will be required to define whether a deficiency in placental IL-10 during pregnancy is involved in the pathogenesis of IUGR. If so, new possibilities for prophylaxis and treatment of IUGR might become available. This is of interest inasmuch as IUGR is such an important risk factor for newborns, especially in poor countries $(25,26)$ and not only in malnourished, but also in well-nourished populations.

Acknowledgments. The authors thank Florence Härling for very skilful technical assistance, Ellen Samuelsson for collecting and taking good care of the placenta samples, and Dr. Theresa Powell for helping out with the tissue sampling when there were problems. 


\section{REFERENCES}

1. Wegmann TG 1988 Maternal T-cells promote placental growth and prevent spontaneous abortion. Immunol Letter 17:297-302

2. Wegmann TG, Lin H, Guilbert L, Mosmann TR 1993 Bidirectional cytokine interactions in the maternal-fetal relationship: is successful pregnancy a TH2 phenomenon? Immunol Today 14:353-356

3. Marzi M, Vigano A, Trabattoni D, Villa ML, Salvaggio A, Clerici E, Clerici M 1996 Characterization of type 1 and type 2 cytokine production profile in physiologic and pathologic human pregnancy. Clin Exp Immunol 106:127-133

4. Hill JA, Polgar K, Anderson DJ 1995 T-helper 1-type immunity to trophoblast in women with recurrent spontaneous abortion. JAMA 24:1933-1936

5. Chaouat G, Menu E, Clark DA, Dy M, Minkowski M, Wegmann TG 1990 Control of fetal survival in CBA x DBA/2 mice by lymphokine therapy. J Reprod Fertil $89: 447-458$

6. Chaouat G, Meliani AA, Martal J, Raghupathy R, Elliot J, Mosmann T, Wegmann TG 1995 IL-10 prevents naturally occurring fetal loss in the CBA x DBA/2 mating combination, and local defect in IL-10 production in this abortion-prone combination is corrected by in vivo injection of IFN- $\tau$. J Immunol 154:4261-4268

7. Lohler KR, Rennick D, Rajewsky K, Muller W 1993 Interleukin-10 deficient mice develop chronic enterocolitis. Cell 75:263-274

8. Rijhhsinghani AG, Thompson K, Tygrette L, Bhatia SK 1997 Inhibition of interleukin-10 during pregnancy results in neonatal growth retardation. Am J Reprod Immunol 37:232-235

9. Marsal K, Persson P-H, Larsen T, Lilja H, Selbing A, Sultan B 1996 Intrauterine growth curves based on ultrasonically estimated foetal weights. Acta Paediat 85:843848

10. Laurin J, Lingman G, Marsal K, Persson P-H 1987 Fetal blood flow in pregnancies complicated by intrauterine growth retardation. Obstet Gynecol 69:895-902

11. Rennick D, Davidson N, Berg D 1995 Interleukin-10 knockout mice: a model of chronic inflammation. Clin Immunol Immunopathol 76:174-178

12. Ragupathy R, Makhseed M, Azizieh F, Hassan N, Al-Azemi M, Al-Shamali E 1999 Maternal TH1- and TH2-type reactivity to placental antigens in normal human pregnancy and unexplained recurrent spontaneous abortions. Cell Immunol 196:122130

13. Benyo DF, Miles TM, Conrad KP 1997 Hypoxia stimulates cytokine production by villous explants from the human placenta. J Clin Endocrinol Metab 82:1582-1588
14. Chernoff AE, Granowitz EV, Shapiro L, Vannier E, Lonnemann G, Angel JB, Kennedy JS, Rabson AR, Wolff SM, Dinarello CA 1995 A randomized, controlled trial of IL-10 in humans. J Immunol 154:5492-5499

15. Fuchs AC, Granowitz EV, Shapiro L, Vannier E, Lonnemann G, Angel JB, Kennedy JS, Rabson AR, Radwanski E, Affrime MB, Cutler DL, Grint PC Dinarello CA 1996 Clinical, haematologic and immunologic effects of interleukin-10 in humans. J Clin Immunol 16:291-303

16. Marchant A, Amraoui Z, Gueydan C, Bruyns C, Le Moine O, Vandenabeele P, Fiers W, Buurman WA, Goldman M 1996 Methylprednisolone differentially regulates IL-10 and tumor necrosis factor (TNF) production during murine endotoxaemia. Clin Exp Immunol 106:91-96

17. Redman CWG, Sacks GP, Sargent IL 1999 Preeclampsia: an excessive inflammatory response to pregnancy. Am J Obstet Gynecol 180:499-506

18. Hennessy A, Pilmore HL, Simmons LA, Painter DM 1999 A deficiency of placental IL-10 in preeclampsia. J Immunol 163:3491-3495

19. Nakabayashi M, Sakura M, Takeda Y, Sato K 1998 Elevated IL-6 in midtrimester amniotic fluid is involved with the onset of preeclampsia. Am J Reprod Immunol 39:329-334

20. Winkler M, Fischer DC, Ruck P, Marx T, Kaiserling E, Oberpichler A, Tschesche H, Rath W 1999 Parturition at term: parallel increases in interleukin- 8 and proteinase concentrations and neutrophil count in the lower uterine segment. Hum Reprod $14: 1096-1100$

21. Hu DE, Hori G, Fan TP 1993 Interleukin-8 stimulates angiogenesis in rats. Inflammation 17:135-143

22. Kelly RW, Leask R, Calder AA 1992 Choriodecidual production of interleukin -8 and mechanism of parturition. Lancet 339:776-777

23. Romero R, Ceska M, Avila C, Mazor M, Behnke E, Lindley E 1991 Neutrophil attractant/activating peptide-1/interleukin- 8 in term and preterm parturition. Am J Obstet Gynecol 165:813-820

24. Sennstrom MB, Ekman G, Westergren-Thorsson G, Malmstrom A, Bystrom B, Endresen U, Mlambo N, Norman M, Stabi B, Brauner A 2000 Human cervical ripening, an inflammatory process mediated by cytokines. Mol Hum Reprod 6:375381

25. Jalil F, Lindblad BS, Hanson LÅ, Khan SR, Yaqoob M, Karlberg J 1993 Early child health in Lahore, Pakistan; IX. Perinatal events. Acta Paediatr Suppl 390:95-107

26. Fikree FF, Berendes HW 1994 Risk factors for term intrauterine growth retardation: a community-based study in Karachi. Bull WHO 72:581-587 